\title{
Voluntary Running Exercise-Mediated Enhanced Neurogenesis Does Not Obliterate Retrograde Spatial Memory
}

\author{
Maheedhar Kodali, ${ }^{1,2,3}$ Tarick Megahed, ${ }^{1}$ Vikas Mishra, ${ }^{1,2,3}$ Bing Shuai, ${ }^{1,2,3}$ Bharathi Hattiangady, ${ }^{1,2,3}$ \\ and $\odot$ Ashok K. Shetty ${ }^{1,2,3}$ \\ ${ }^{1}$ Institute for Regenerative Medicine, Texas A\&M Health Science Center College of Medicine at Scott and White, Temple, Texas $76502,{ }^{2}$ Research Service, \\ Olin E. Teague Veterans' Medical Center, Central Texas Veterans Health Care System, Temple, Texas 76502, and ${ }^{3}$ Department of Molecular and Cellular \\ Medicine, Texas A\&M Health Science Center College of Medicine, College Station, Texas 77843
}

Running exercise (RE) improves cognition, formation of anterograde memories, and mood, alongside enhancing hippocampal neurogenesis. A previous investigation in a mouse model showed that RE-induced increased neurogenesis erases retrograde memory (Akers et al., 2014). However, it is unknown whether RE-induced forgetting is common to all species. We ascertained whether voluntary REinduced enhanced neurogenesis interferes with the recall of spatial memory in rats. Young rats assigned to either sedentary (SED) or running exercise (RE) groups were first subjected to eight learning sessions in a water maze. A probe test (PT) conducted $24 \mathrm{~h}$ after the final training session confirmed that animals in either group had a similar ability for the recall of short-term memory. Following this, rats in the RE group were housed in larger cages fitted with running wheels, whereas rats in the SED group remained in standard cages. Animals in the RE group ran an average of $78 \mathrm{~km}$ in 4 weeks. A second PT performed 4 weeks after the first PT revealed comparable ability for memory recall between animals in the RE and SED groups, which was evidenced through multiple measures of memory retrieval function. The RE group displayed a 1.5- to 2.1-fold higher hippocampal neurogenesis than SED rats. Additionally, both moderate and brisk RE did not interfere with the recall of memory, although increasing amounts of RE proportionally enhanced neurogenesis. In conclusion, RE does not impair memory recall ability in a rat model despite substantially increasing neurogenesis.

Key words: forgetting; hippocampal neurogenesis; memory recall; memory retrieval; running exercise; water maze test

Significance Statement

Running exercise (RE) improves new memory formation along with an increased neurogenesis in the hippocampus. In view of a recent study showing that RE-mediated increased hippocampal neurogenesis promotes forgetfulness in a mouse model, we ascertained whether a similar adverse phenomenon exists in a rat model. Memory recall ability examined 4 weeks after learning confirmed that animals that had run a mean of $78 \mathrm{~km}$ and displayed a 1.5- to 2.1-fold increase in hippocampal neurogenesis demonstrated similar proficiency for memory recall as animals that had remained sedentary. Furthermore, both moderate and brisk RE did not interfere with memory recall, although increasing amounts of RE proportionally enhanced neurogenesis, implying that RE has no adverse effects on memory recall.

\section{Introduction}

Running exercise (RE) improves physical and mental health (Hötting and Röder, 2013; Hamilton and Rhodes, 2015). Among the brain plasticity induced by RE, enhanced hippocampal neurogenesis has received considerable attention because of its perceived role in forming new memories and improving mood (Kempermann et al., 2015; Miller and Hen, 2015). Indeed, studies using genetic modifications have demonstrated that increased

article suggest the views of authors and do not represent the views of the U.S. Department of Veterans Affairs or the United States Government. We thank Luciano Silveira for assisting with the preparation of figures and Xiaolan Rao for technical assistance.

The authors declare no competing financial interests.

Correspondence should be addressed to Dr. Ashok K. Shetty, Texas A\&M Health Science Center College of Medicine, 5701 Airport Road, Module C, Temple, TX 76502. E-mail: Shetty@medicine.tamhsc.edu.

DOI:10.1523/JNEUROSCI.0766-16.2016

Copyright $\odot 2016$ the authors $\quad 0270-6474 / 16 / 368112-11 \$ 15.00 / 0$ 


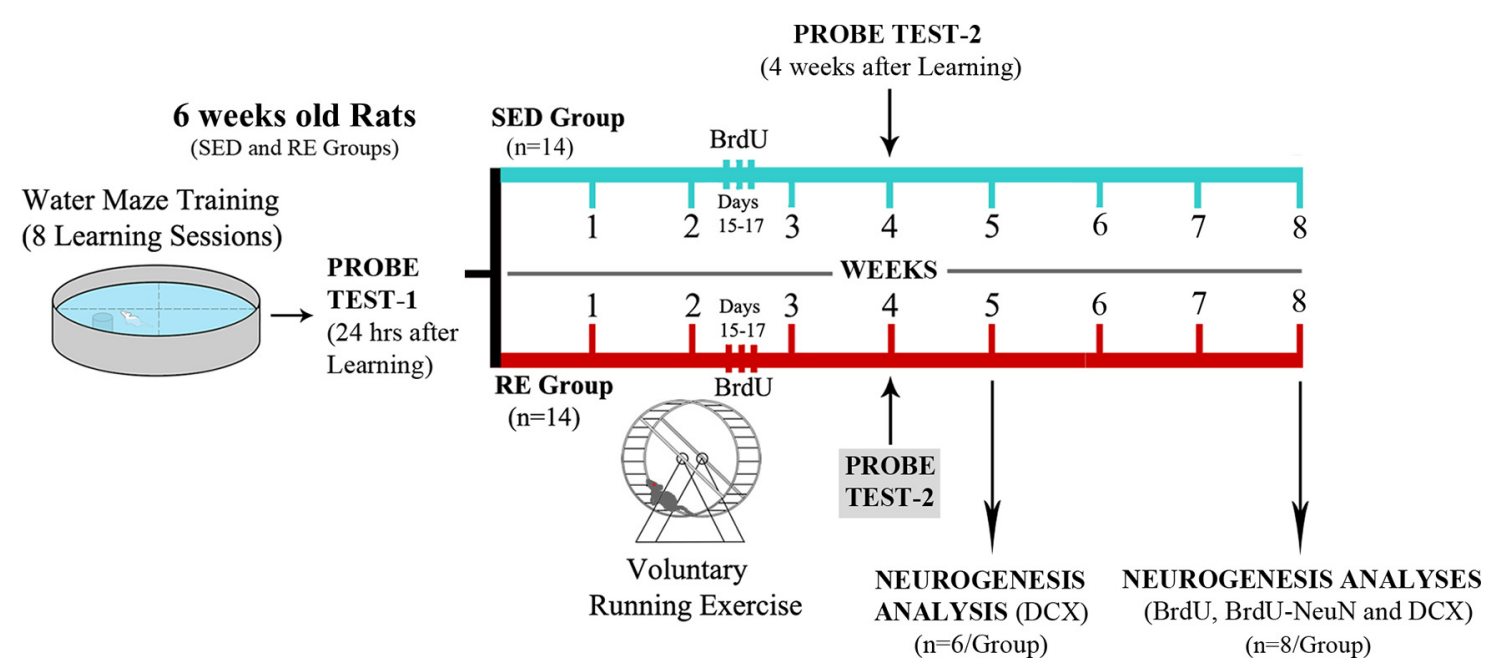

Figure 1. A schematic representation of the experimental design and the timeline of the experiments. Young Sprague Dawley rats were first randomly assigned to either sedentary (SED) or running exercise (RE) groups ( $n=14$ /group) but housed in standard cages. Next, animals in both groups underwent water maze training comprising 8 learning sessions over $8 \mathrm{~d}$. An initial probe test (Probe Test 1 ) was conducted $24 \mathrm{~h}$ after the final learning session to detect any difference between the two groups in memory retrieval. Following this, animals in the SED group were continued to be housed in standard cages ( 2 rats per cage), but animals belonging to the RE group were individually housed in larger cages fitted with running wheels to facilitate daily voluntary running exercise. After 4 weeks of housing as above, animals in both groups were examined with a second probe test (Probe Test 2). A week later, subgroups from the SED and RE groups ( $n=6 / \mathrm{group}$ ) were killed using intracardiac perfusions with $4 \%$ paraformaldehyde, and brain tissues were processed to analyze hippocampal neurogenesis using doublecortin (DCX) immunostaining. The remaining animals ( $n=8 /$ group) were maintained in their respective housing conditions and killed after 8 weeks of housing using intracardiac perfusions. These animals also received three injections of $5^{\prime}$-bromodeoxyuridine (BrdU) in the third week (once daily for $3 \mathrm{~d}$ on days 15-17) of the experiment to facilitate the quantification of net hippocampal neurogenesis through BrdU immunostaining and BrdU-NeuN dual immunofluorescence methods. The tissues were also used to quantify the status of neurogenesis via DCX immunostaining.

neurogenesis can enhance cognition and memory in both physiological and pathological conditions (Costa et al., 2015). The beneficial effects of RE associated with enhanced neurogenesis include improved performance in learning tasks (van Praag et al., 1999), alleviation of age-related stress and learning impairments (van Praag et al., 2005; Kannangara et al., 2011), and restrained disease progression or improved cognition in subjects afflicted with neurodegenerative diseases (Adlard et al., 2005; Hoveida et al., 2011). Additional studies have demonstrated that physical exercise facilitates faster recovery and less severe cognitive impairment or neurological deficits after brain insults. This has been observed in animal prototypes subjected to whole-brain irradiation (Wong-Goodrich et al., 2010), chemotherapy (Winocur et al., 2014), status epilepticus (Gomes et al., 2014), traumatic brain injury (Jacotte-Simancas et al., 2015); chronic stress (Kim and Leem, 2016); ischemic stroke (Ahn et al., 2016); Huntington's disease (Ji et al., 2015); and Alzheimer's disease (Ryan and Kelly, 2016).

A vast majority of studies on hippocampal neurogenesis and memory were, however, focused on examining the anterograde effects of neurogenesis manipulation on memory formation, which consistently demonstrated memory augmentation with increased neurogenesis (Deng et al., 2010). However, two recent studies examining the effects of RE-induced enhanced neurogenesis on memory retrieval in C57BL/6 mice demonstrated that increased hippocampal neurogenesis interferes with the recall of retrograde memory in contextual fear conditioning and spatial reference memory tests (Akers et al., 2014; Epp et al., 2016). Authors have proposed that, because successful memory recall requires reactivation of patterns of neural activity present at the time of memory encoding (Danker et al., 2010; Liu et al., 2012; Richards and Frankland, 2013), an increased addition of newly born neurons to the hippocampus circuitry obliterates retrograde memory through reconfiguration of dentate gyrus
(DG)-CA3 circuits. This is consistent with the prediction in computational models that reconfiguration of DG-CA3 circuits would reduce the ability of a given set of cues to reinvoke the same pattern of activity that was present at the time of memory encoding, which in turn would cause interference during the retrieval of memories (Weisz and Argibay, 2012).

Nonetheless, it is unknown whether: (1) RE-induced increased neurogenesis can expunge all types of retrograde memory or only certain types of memories; (2) a moderate increase in neurogenesis is adequate for obliterating retrograde memories; and (3) RE-induced forgetting is common to all mammalian species. We investigated whether voluntary RE-induced increased neurogenesis hinders the recall of spatial reference memory in rats. Two cohorts of young rats ascribed to either sedentary (SED) or RE groups were subjected to eight learning sessions in a water maze. A probe test (PT) performed $24 \mathrm{~h}$ after the final training session established similar competence for the recall of short-term memory in either group. Subsequently, rats in the RE group were housed in larger cages fitted with running wheels, whereas rats in the SED group remained in standard cages. A second PT was conducted 4 weeks after the first PT to examine the ability of animals belonging to either the RE or SED group for recalling spatial memory, and neurogenesis was quantified to examine whether memory recall function correlated with the extent of neurogenesis.

\section{Materials and Methods}

Animals and experimental design. This study used 6-week-old male Sprague Dawley rats obtained from Harlan Sprague Dawley. The combined institutional animal care and use committee of the Central Texas Veterans Health Care System, Texas A\&M Health Science Center College of Medicine and Scott and White Hospital approved all experiments performed in this study. Rats $(n=28)$ were first screened for hippocampus-dependent spatial learning and memory function using a Morris water maze test (WMT). Figure 1 illustrates the timeline of various analyses performed on these rats. Two cohorts of young rats were 

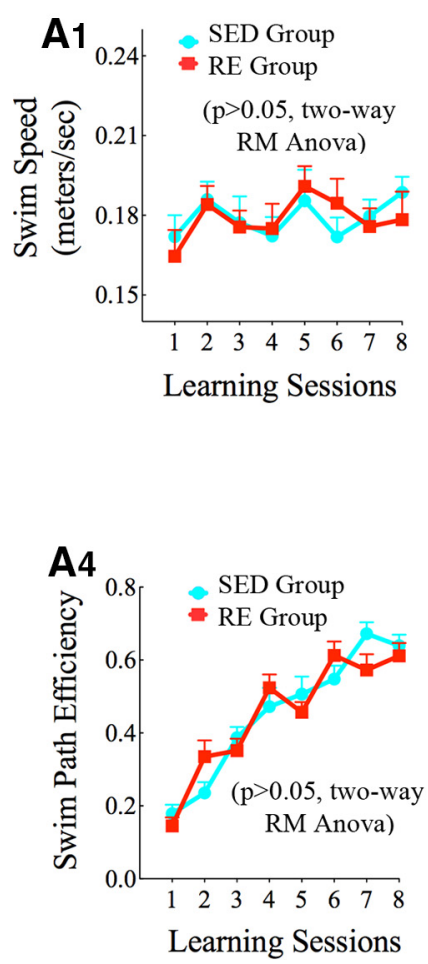
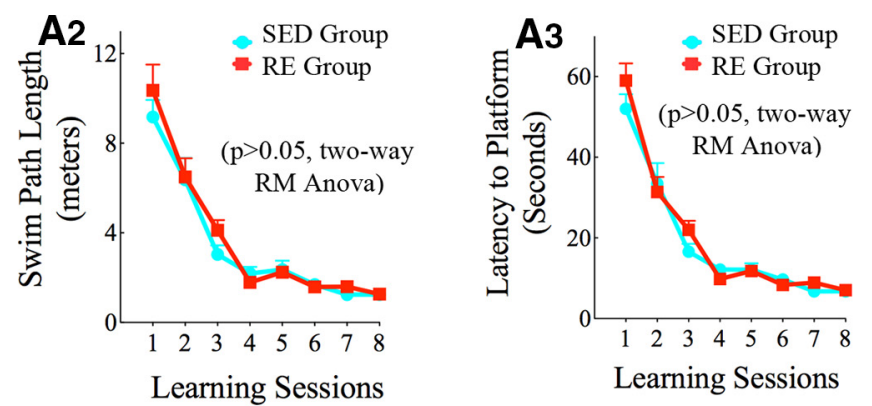

PROBE TEST-1

(24 hrs after Learning)

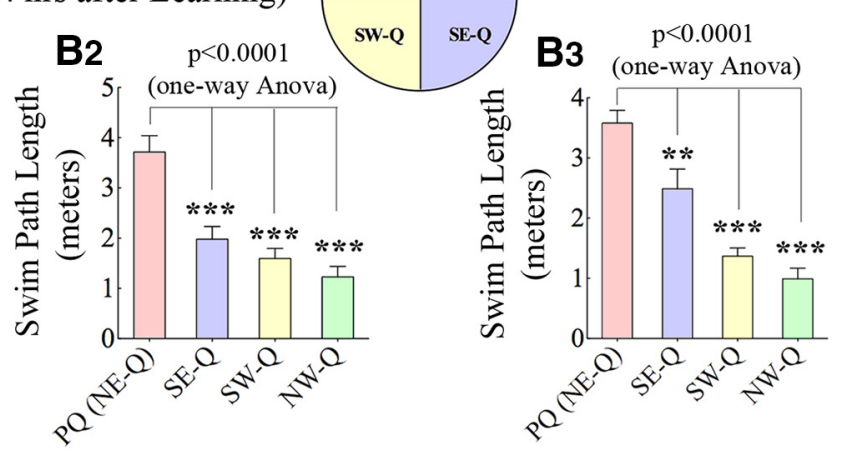

\section{B4}

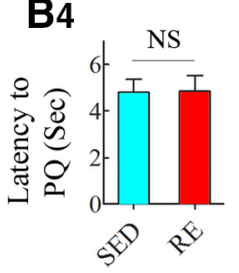

B5

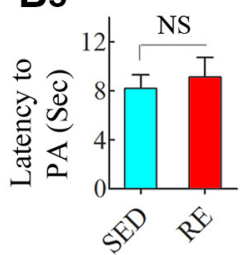

B6

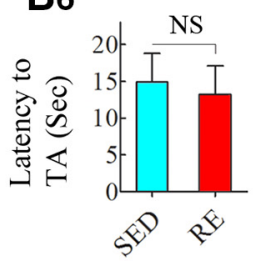

B7

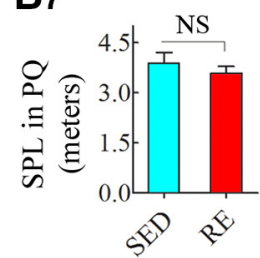

B8

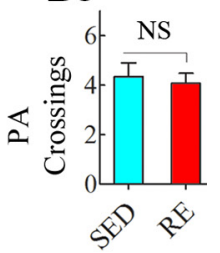

PROBE TEST-2 (4 Weeks after Learning)
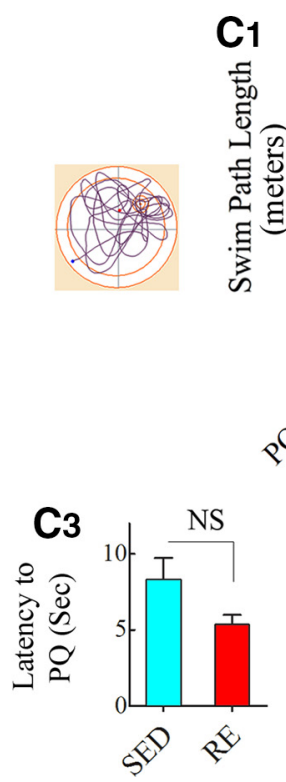
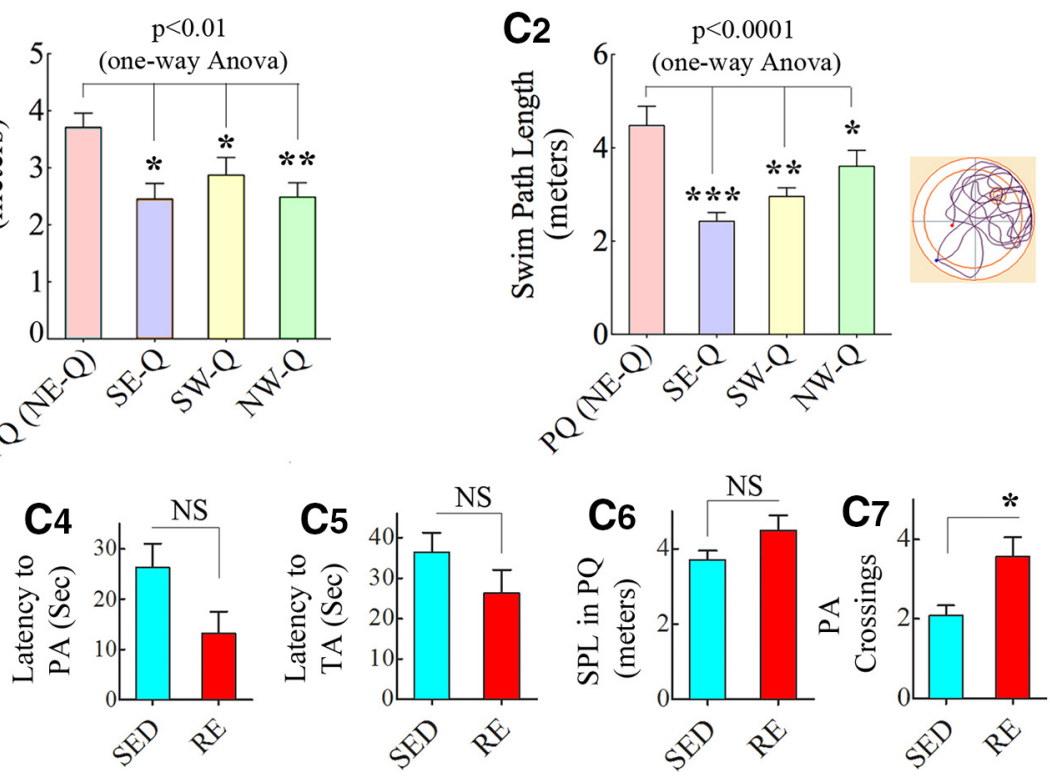

Figure 2. $\quad A_{1}-B_{8^{\prime}}$ Comparison of the spatial learning and memory performance between the two groups of young Sprague Dawley rats assigned to the sedentary (SED) or running exercise (RE) groups, before the commencement of voluntary exercise regimen. Two-way repeated-measures ANOVA revealed no differences between the two groups for swim speeds $\left(\boldsymbol{A}_{1} ; \boldsymbol{p}>0.05\right)$, swim path lengths (SPLs), and latencies to reach the platform $\left(A_{2}, A_{3} ; p>0.05\right)$, or swim path efficiency values $\left(A_{4}, p>0.05\right)$ in different learning sessions. The probe test conducted $24 \mathrm{~h}$ after the final learning session also revealed no differences between the two groups $\left(\boldsymbol{B}_{1}-\boldsymbol{B}_{\boldsymbol{g}}\right)$. Both groups showed greater affinity for the platform quadrant, in comparison with the other three quadrants of the pool (one-way ANOVA, $p<0.0001 ; \boldsymbol{B}_{2}, \boldsymbol{B}_{3}$ ). Additional parameters of memory retrieval ability, such as latencies to reach the platform quadrant (PQ; $\boldsymbol{B}_{4}$ ), platform area (Figure legend continues.) 
first assigned to SED and RE groups and subjected to eight learning sessions in the water maze. This was followed by a PT at $24 \mathrm{~h}$ after the final training session, which confirmed similar proficiency of animals in either group for the recall of short-term memory. Subsequently, animals belonging to the RE group were housed individually in larger cages fitted with running wheels $(n=14)$, whereas rats in the SED group were maintained two per cage in standard cages $(n=14)$. A second PT was conducted after 4 weeks of housing to determine the spatial memory recall ability of animals in the RE or SED group at an extended time-point after learning and memory encoding. Subgroups of rats ( $n=6$ /group) were killed a week after the second PT and brain tissues were processed for stereological quantification of doublecortin-positive $\left(\mathrm{DCX}^{+}\right)$neurons in the subgranular zone-granule cell layer (SGZ-GCL) of the DG. This facilitated the quantification of the extent of the increase in neurogenesis in the RE group with $\sim 5$ weeks of exercise regimen, in comparison with the SED group. Additional subgroups of rats in both groups ( $n=8$ /group) received daily injections of $5^{\prime}$-bromodeoxyuridine (BrdU) $(100 \mathrm{mg} / \mathrm{kg})$ on housing days 15-17 (i.e., the third week of exercise in the RE group), to label cells and neurons that were born during this period in the hippocampus. These animals were housed similarly as described above until killed $\sim 5.5$ weeks after the last BrdU injection (equivalent to after 8 weeks of exercise in the RE group). The brain tissues were processed for BrdU immunostaining, a BrdU-neuron-specific nuclear antigen $(\mathrm{NeuN})$ dual immunofluorescence procedure, and quantification of net neurogenesis. This enabled measurement of the increase in net neurogenesis with 15-17 d of exercise in the RE group, in comparison with the SED group.

WMT. The Morris WMT is one of the most widely accepted tests for measuring hippocampal-dependent spatial learning and memory function in rodents. The learning paradigm used in this study is detailed in our previous studies (Hattiangady et al., 2011; Parihar et al., 2011, 2013; Hattiangady and Shetty, 2012; Kodali et al., 2015). In brief, it comprised eight learning sessions over $8 \mathrm{~d}$ with four acquisition trials per session. Rats were trained to find the circular platform submerged in the water using spatial cues. The movement of the rat was continuously videotracked and recorded using the computerized ANY-maze video-tracking system. Each trial lasted $90 \mathrm{~s}$, and the intertrial interval was $60 \mathrm{~s}$. The rat was placed in the water facing the wall of pool in a pseudo-random manner so that each trial commenced from a different start location. Once the rat reached the platform, it was allowed to stay there for $30 \mathrm{~s}$. When a rat failed to find the platform within the ceiling period, it was guided to the platform where it was allowed to stay for $30 \mathrm{~s}$. The location of the platform remained constant across all days and trials for an individual animal. Latencies and swim path lengths (SPLs) to reach the platform, swim path efficiencies, and swim speeds were calculated and collected using ANY-maze software. Mean SPLs to reach the platform in different learning sessions were used to assess learning.

Two PTs were conducted in this study: one at $24 \mathrm{~h}$ and another at 4 weeks after the final learning session. For these, the platform was removed and rats were released from the quadrant opposite to the original position of the platform. Animals received a single trial for $45 \mathrm{~s}$ in the first

\section{$\leftarrow$}

(Figure legend continued.) $\quad\left(\mathrm{PA} ; \boldsymbol{B}_{5}\right)$, and target area (TA; $\left.\boldsymbol{B}_{6}\right), S P L s$ in the platform quadrant $\left(\boldsymbol{B}_{7}\right)$, and platform area crossings $\left(\boldsymbol{B}_{8}\right)$, were also comparable between the two groups $(p>$ 0.05 , two tailed, unpaired Student's $t$ test). $C_{7}-C_{7}$, Comparison of memory retrieval ability in the second probe test performed after 4 weeks of housing in standard cages (SED group) or cages fitted with running wheels (RE group) following the first probe test. Animals belonging to both SED $\left(\boldsymbol{C}_{1}\right)$ and RE $\left(\boldsymbol{C}_{2}\right)$ groups exhibited a clear affinity for the PQ over the other three quadrants ( $p<0.01-0.0001$, one-way ANOVA), implying a clear proficiency for recalling memories that were formed 4 weeks earlier. Additional parameters of memory retrieval ability, such as latencies to reach the $\mathrm{PQ}\left(\boldsymbol{C}_{3}\right)$, platform area $\left(\mathrm{PA} ; \boldsymbol{C}_{4}\right)$, and target area $\left(\mathrm{TA} ; \boldsymbol{C}_{5}\right)$, and SPLS in the $\mathrm{PQ}\left(\boldsymbol{C}_{\boldsymbol{\sigma}}\right)$, were also comparable between the two groups $(p>0.05$, two tailed, unpaired Student's $s$ test). Moreover, animals in the RE group exhibited greater numbers of platform area crossings compared with animals in the SED group $\left(\boldsymbol{C}_{7} ; p<0.05\right)$, suggesting a relatively better memory recall ability with exercise after learning. $\mathrm{PQ}(\mathrm{NE}-\mathrm{Q})$ ), Platform quadrant (northeast quadrant); $\mathrm{SE}-\mathrm{Q}$, southeast quadrant; $\mathrm{SW}-\mathrm{Q}$, southwest quadrant; NS, not significant; NW- $\mathrm{Q}$, northwest quadrant. ${ }^{*} p<0.05 .{ }^{* *} p<0.01 .{ }^{* * *} p<0.001$. NS, Not significant.
PT because this test was conducted $24 \mathrm{~h}$ after the last learning session. In the second PT performed 4 weeks after the first PT, animals received two probe trials, each lasting $60 \mathrm{~s}$ and separated by $2 \mathrm{~min}$. Data from the second trial were computed for analyses, as probe trials were conducted at an extended time-point after the last learning session. Two trial probe tests have been performed in previous studies examining the retention of spatial memory at extended periods after learning (Clark et al., 2007). The first trial served to reorient the animal to the water maze pool and spatial cues whereas the second trial examined its memory retrieval ability using spatial cues. The reorientation or reminder experience in probe trial 1 is believed to manifest as a performance that is significantly above chance on probe trial 2 (Clark et al., 2007). Indeed, animals from both the RE and SED groups showed greater SPLs in the platform quadrant in the second trial. The overall performance in probe trials was examined in detail by measuring SPLs in the platform quadrant compared with other quadrants of the pool, dwell times in the platform quadrant, number of entries to the platform quadrant and platform area, and latencies to entering the platform and target areas.

Housing of animals belonging to RE and SED groups. Following the water maze learning sessions and the first PT, animals assigned to the RE group were housed individually in larger cages fitted with running wheels and were given ad libitum access to wheels, food and water until killed. Animals belonging to the SED group were housed in pairs in standard cages with ad libitum access to food and water until killed.

$D C X$ and BrdU immunohistochemistry. Animals were perfused with 4\% paraformaldehyde (PFA) at time-points described earlier, and fixed brains were processed for immunohistochemical analyses, as described in our previous reports (Rao et al., 2005, 2006, 2007). In brief, each brain was cut coronally through the entire hippocampus using a cryostat and $30-\mu \mathrm{m}$-thick sections were collected serially. Serial sections (every 15th) were picked from each animal and processed separately for DCX or BrdU immunostaining, using methods described in our previous reports (Rao and Shetty, 2004; Rao et al., 2005, 2006, 2007; Kodali et al., 2015). Primary antibodies comprised goat anti-DCX from Santa Cruz Biotechnology and mouse anti-BrdU from BD Biosciences. Secondary antibodies and $\mathrm{ABC}$ reagents were obtained from Vector Labs.

Quantification of numbers of DCX ${ }^{+}$neurons and $B r d U^{+}$cells in the SGZ-GCL. Serial sections stained for DCX and BrdU were used for the stereological quantification of absolute numbers of $\mathrm{DCX}^{+}$and $\mathrm{BrdU}^{+}$ cells in the SGZ-GCL, using a StereoInvestigator system (Microbrightfield) comprising a color digital video camera (Optronics) interfaced with a Nikon E600 microscope (Nikon Instruments). The stereological methods used are detailed in our previous reports (Rao and Shetty, 2004; Rao et al., 2005, 2006; Hattiangady and Shetty, 2008). In each animal, $\mathrm{DCX}^{+}$and $\mathrm{BrdU}^{+}$cells were counted using $100 \times$ oil-immersion lens from counting frame locations (each measuring $40 \times 40 \mu \mathrm{m}, 0.0016$ $\mathrm{mm}^{2}$ area) placed randomly and systematically in every 15 th section throughout the entire hippocampus. The Gundersen coefficient error (CE) in this study varied from 0.08 to 0.15 for different animals.

Analyses of NeuN expression in $\mathrm{BrdU}^{+}$cells. To visualize the fraction of $\mathrm{BrdU}^{+}$cells that differentiated into mature neurons, a dual immunofluorescence method for BrdU and NeuN was used, as described in our previous studies (Rao et al., 2005; Shetty et al., 2012; Kodali et al., 2015). Briefly, visualization of BrdU immunofluorescence involved overnight incubation in a rat anti-BrdU antibody (1:200; Serotec) followed by a $1 \mathrm{~h}$ treatment with an anti-rat AlexaFluor-594 secondary antibody (1:200; Invitrogen). Following this, NeuN expression was visualized through overnight incubation in a mouse anti-NeuN antibody (1:1000; Millipore) followed by $1 \mathrm{~h}$ incubation in an anti-mouse AlexaFlour-488 secondary antibody (1:200; Invitrogen). The sections were washed thoroughly, mounted on subbed slides using a slowfade-antifade mounting medium (Invitrogen), and analyzed using a laser scanning confocal microscope (Nikon Instruments). $Z$-stacks with a $1 \mu \mathrm{m}$ interval were taken through the SGZ-GCL from multiple sections in each animal. These stacks were analyzed to identify and quantify cells dual labeled for BrdU and NeuN among all the $\mathrm{BrdU}^{+}$cells, and the percentages of $\mathrm{BrdU}^{+}$cells expressing NeuN were computed for both groups. This quantification involved analyses of $70-90 \mathrm{BrdU}^{+}$cells per animal ( $n=6$ /group) in both groups. 

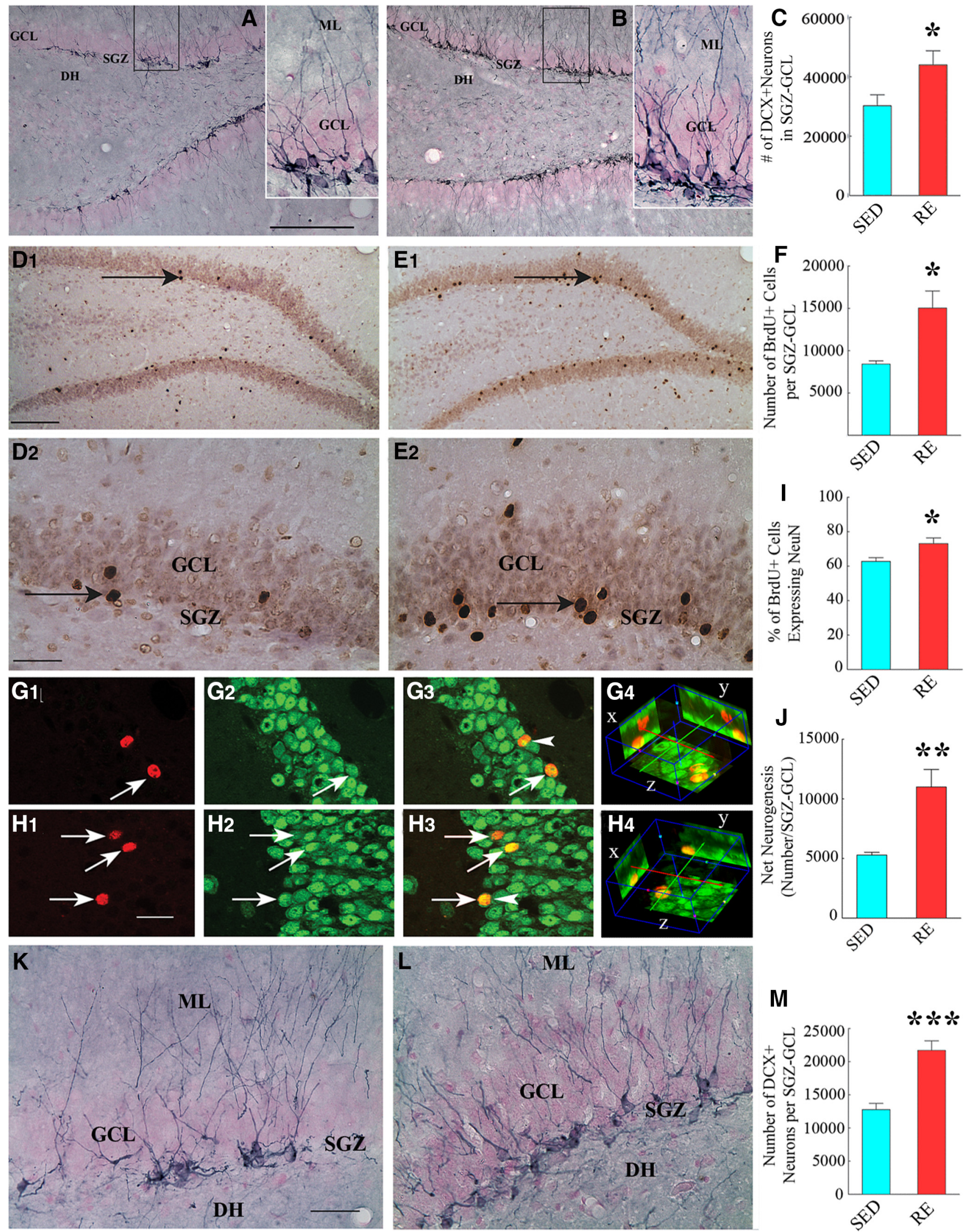

\section{M}

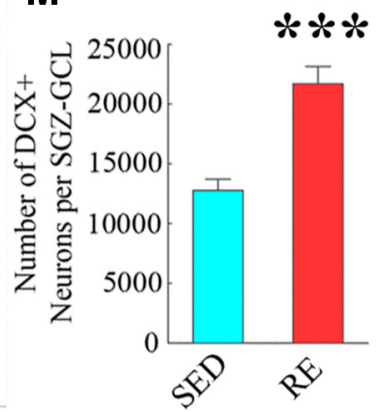

Figure 3. $\boldsymbol{A}-\boldsymbol{C}$, Five weeks of running exercise (RE) enhanced the production of newly born neurons expressing doublecortin (DCX) in the subgranular zone-granule cell layer ( $S G Z-G C L)$ of the DG. $\boldsymbol{A}, \boldsymbol{B}$, Distribution of $\mathrm{DCX}{ }^{+}$newly born neurons in the SGZ-GCL of a sedentary (SED) animal $(\boldsymbol{A})$ and an animal that underwent RE for 5 weeks $(\boldsymbol{B})$. Insets, Magnified views of regions from $\boldsymbol{A}, \boldsymbol{B}$. $\boldsymbol{C}$, Bar chart compares the numbers of $D C X^{+}$newly born neurons between SED and RE groups. Note an enhanced production of newly born neurons in RE animals, in comparison with SED animals ( $p<$ 0.05 , two tailed, unpaired Student's $t$ test). DH, Dentate hilus; ML, molecular layer. $\boldsymbol{D}_{\mathbf{1}}-\boldsymbol{M}$, Measurement of net hippocampal neurogenesis in the third week of RE (Figure legend continues.) 
Statistical analyses. First, SPLs and latencies to the hidden platform, and swim path efficiency values in rats assigned to the RE and SED groups were separately analyzed using one-way repeated-measures ANOVA followed by Newman-Keuls post hoc tests. Next, we compared swim speeds, SPLs, and latencies to the hidden platform, and swim path efficiency values between rats assigned to the RE and SED groups using two-way repeated-measures ANOVA followed by Bonferroni post hoc tests. Comparisons of SPLs and dwell times between different quadrants of the pool in the probe tests were performed using one-way ANOVA followed by Newman-Keuls multiple-comparisons test. Comparisons between RE and SED groups for probe test parameters, such as SPLs and dwell times in the platform quadrant, latencies to the platform and target areas, and platform area crossings used an unpaired, two-tailed Student's $t$ test. All parameters of neurogenesis across the RE and SED groups were also compared using an unpaired, two-tailed Student's $t$ test.

\section{Results}

Animals assigned to the RE or SED group displayed similar ability for spatial learning and short-term memory

Young adult rats displayed an excellent ability to locate the submerged platform in the learning sessions. Comparison of various data revealed a similar ability for spatial learning between animals assigned to either the RE and SED groups (Fig. 2; $n=14$ /group). We first analyzed learning through one-way repeated-measures ANOVA, which demonstrated a progressive decline in both SPL and latency to reach the hidden platform over learning sessions (Fig. $2 A_{2}, A_{3}$ ). These declines were similar in animals assigned to RE or SED groups (SPL, $F_{(7,111)}=38-49, p<0.0001$; latency, $\left.F_{(7,111)}=52-69, p<0.0001\right)$. Consistent with these, swim path efficiency values increased across learning sessions in both groups $\left(F_{(7,111)}=28-38, p<0.0001\right.$; Fig. $\left.2 A_{4}\right)$. Next, we compared the two groups for various parameters through two-way repeatedmeasures ANOVA, which revealed the following findings: (1) Swim speeds were comparable across learning sessions $\left(F_{(7,182)}=\right.$ 1.9, $p>0.05$; Fig. $\left.2 A_{1}\right)$ and between the two groups $\left(F_{(1,26)}=\right.$ $0.00, p>0.05$; Fig. $\left.2 A_{1}\right)$. (2) Learning curves showed a progressive decline in SPL and latency to reach the hidden platform in the first four learning sessions, implying an ability for spatial learning $\left(F_{(7,182)}=83-120, p<0.0001\right.$; Fig. $\left.2 A_{2}, A_{3}\right)$. Notably, both SPLs and latencies plateaued in the last four learning sessions, implying the occurrence of memory consolidation processes. Learning curves were similar between the two groups based on both SPLs and latencies $\left(F_{(1,26)}=0.4, p>0.05\right.$; Fig. $\left.2 A_{2}, A_{3}\right)$. (3) Swim path efficiency values increased over learning sessions $\left(F_{(7,182)}=63\right.$, $p<0.0001)$, and swim path efficiency curves were equivalent between the two groups $\left(F_{(1,26)}=0.01, p>0.05\right.$; Fig. $\left.2 A_{4}\right)$. Furthermore, the PT performed $24 \mathrm{~h}$ after the final learning session

\section{$\leftarrow$}

(Figure legend continued.) and the status of hippocampal neurogenesis after 8 weeks of RE revealed considerable augmentation of neurogenesis with RE. $\boldsymbol{D}_{1}, \boldsymbol{E}_{1}$, Examples of newly born cells expressing $5^{\prime}$-bromodeoxyuridine (BrdU) in the SGZ-GCL from an SED rat $\left(\boldsymbol{D}_{1}\right)$ and a rat that underwent 8 weeks of $R E\left(E_{1}\right)$. In these animals, BrdU was administered in the third week of RE for 3 consecutive days, and BrdU analysis was performed after 8 weeks of RE. D2, E2, Magnified views of regions from $D_{1}, E_{1}, G_{1}-G_{3}, H_{1}-H_{3}$, Examples of $B r d U^{+}$newly born cells that have differentiated into NeuN-expressing mature dentate granule cells in a rat from the SED group $\left(\boldsymbol{G}_{1}-\boldsymbol{G}_{3}\right)$ and a rat from the RE group $\left(\boldsymbol{H}_{1}-\boldsymbol{H}_{3}\right) . \boldsymbol{G}_{\mathbf{4}}, \boldsymbol{H}_{\mathbf{4}}$, Three-dimensional views of $\mathrm{BrdU}^{+}$cells expressing NeuN that are indicated in $\boldsymbol{G}_{3}, \boldsymbol{H}_{\mathbf{3}}$ (arrowheads). $\boldsymbol{K}, \boldsymbol{L}$, Distribution of $D C X^{+}$newly born neurons in the SGZ-GCL of a SED rat $(\boldsymbol{K})$ and a rat that underwent 8 weeks of $\operatorname{RE}(\boldsymbol{I}) . \boldsymbol{F}, \boldsymbol{I}, J, M$, Bar charts compare the number of newly born BrdU ${ }^{+}$cells $(\boldsymbol{F})$, percentages of newly born cells expressing NeuN $(I)$, net hippocampal neurogenesis $(J)$, and DCX ${ }^{+}$newly born neurons $(M)$ between SED and RE groups. Both net hippocampal neurogenesis and $D C X^{+}$newly born cell counts are greater in RE rats than SED rats $(p<0.05-0.001$, two-tailed, unpaired, Student's $t$ test). Scale bars: $\boldsymbol{A}_{,} \boldsymbol{B}_{1} \boldsymbol{D}_{\boldsymbol{1}}, \boldsymbol{E}_{1}, 200 \mu \mathrm{m} ; \boldsymbol{D}_{2}, \boldsymbol{E}_{2}, 50 \mu \mathrm{m} ; \boldsymbol{G}_{\mathbf{1}}-\boldsymbol{H}_{\mathbf{4}}, 30 \mu \mathrm{m} ; \boldsymbol{K}, \boldsymbol{L}, 50 \mu \mathrm{m}$. $\mathrm{DH}$, Dentate hilus; $\mathrm{ML}$, molecular layer. ${ }^{*} p<0.05$. ${ }^{* *} p<0.01$. ${ }^{* * *} p<0.001$. (i.e., the first PT) revealed a similar ability for spatial memory retrieval between animals assigned to the RE or SED groups. This was evidenced through greater SPLs in the platform quadrant vis-à-vis SPLs in other quadrants of the pool $\left(F_{(3,55)}=27-30, p<\right.$ 0.0001 ; Fig. $\left.2 B_{1}-B_{3}\right)$. Analyses through unpaired two-tailed $t$ tests revealed that multiple additional parameters measured during the PT were also comparable between the two groups $(p>0.05$; Fig. $2 B_{4}-B_{8}$ ). Thus, the two groups were highly comparable in their ability for spatial learning and spatial memory recall at the time of assignment to the RE or SED groups.

\section{Four weeks of exercise did not reduce the ability for spatial memory recall in the $\mathrm{RE}$ group}

Animals in the RE group ran an average of $2.8 \mathrm{~km}$ per day and 78 $\mathrm{km}$ in 4 weeks. Analysis of data from the second PT conducted 4 weeks after the last learning session demonstrated a clear ability for spatial memory recall in both RE and SED groups. This is typified by a preferential searching in the platform quadrant compared with other quadrants of the pool by animals in both groups (Fig. $2 C_{1}, C_{2}$ ). This was evidenced through greater SPLs in the platform quadrant in comparison with SPLs in other quadrants of the pool $\left(F_{(3,55)}=4.6-8.7, p<0.01-0.0001\right.$; Fig. $\left.2 C_{1}, C_{2}\right)$. Additional parameters of memory retrieval, such as latencies to the platform quadrant, platform, and target areas, were also comparable between the two groups $(p>0.05$; Fig. $2 C_{3}-C_{6}$ ). However, the number of platform area crossings were greater for animals in the RE group than animals in the SED group (Fig. $2 C_{7}$ )

\section{RE enhanced the number of $\mathrm{DCX}^{+}$newly born neurons in the hippocampus}

Analyses of the number of $\mathrm{DCX}^{+}$newly born neurons in the SGZ-GCL shortly after the second PT (i.e., after 5 weeks of housing in the running wheel fitted or standard cages) demonstrated a 1.5-fold increase in neurogenesis in the RE group, in comparison with the SED group ( $p<0.05$; Fig. $3 A-C ; n=6$ /group). Because a vast majority of $\mathrm{DCX}^{+}$neurons represent neurons that were generated in the 2-3 weeks before death (Rao and Shetty, 2004), these results suggest that even a relatively short-term RE can enhance neurogenesis considerably in the hippocampus.

\section{RE enhanced net hippocampal neurogenesis}

Administration of BrdU on days 15-17 of housing in the running wheel fitted or standard cages and quantification of $\mathrm{BrdU}^{+}$cells in the SGZ-GCL at 5.5 weeks after the last BrdU injection, revealed a 1.8-fold increase in the addition of newly born cells to the hippocampus of RE rats, in comparison with the hippocampus of SED rats $\left(p<0.05\right.$; Fig. $3 D_{1}-E_{2}, F ; n=8$ /group $)$. In addition, quantification of fractions of newly born cells that differentiated into NeuN-expressing neurons showed increased neuronal differentiation of newly born cells in RE animals $(p<0.05$; Fig. $\left.3 G_{1}-H_{4}, J\right)$. Furthermore, net hippocampal neurogenesis (calculated through the extrapolation of $\mathrm{BrdU}^{+}$cell numbers with the percentages of newly born cells expressing NeuN) in the RE group was 2.1-fold greater than the SED group $(p<0.01$; Fig. $3 J)$. Because BrdU injections were given on days 15-17 of housing in running wheel-fitted cages, these results showed the extent of neurogenesis occurring in the third week of running. Quantification of $\mathrm{DCX}^{+}$neurons in the SGZ-GCL of these animals showed 1.7-fold increased neurogenesis with 8 weeks of $\mathrm{RE}(p<$ 0.001 ; Fig. $3 K-M ; n=8)$. These results suggest that both shortterm ( 5 weeks) and long-term ( 8 weeks) moderate RE leads to a considerable increase in neurogenesis. 
A1

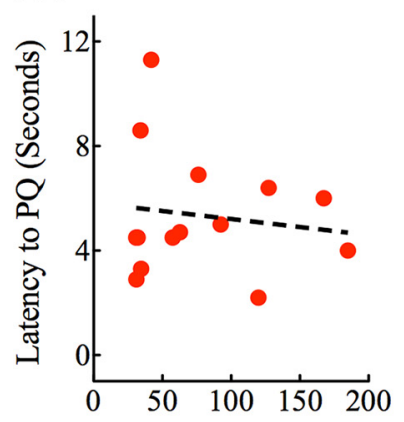

Distance in Kilometers

\section{A4}

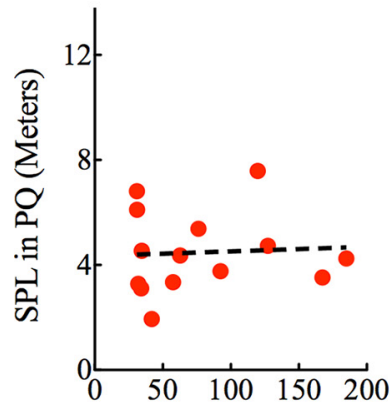

Distance in Kilometers
A2

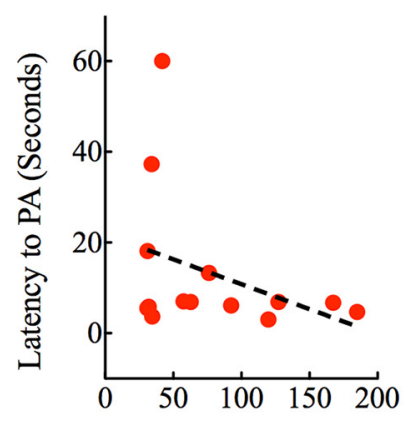

Distance in Kilometers

A5

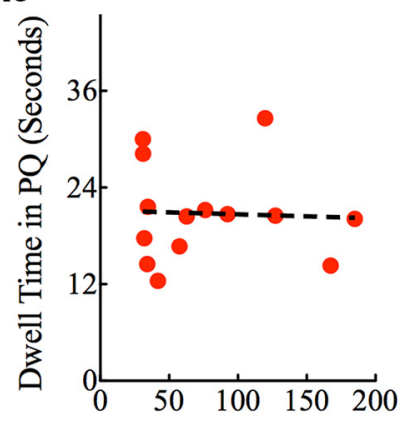

Distance in Kilometers
A3

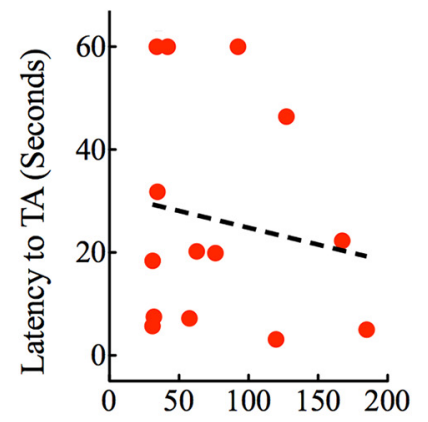

Distance in Kilometers

A6

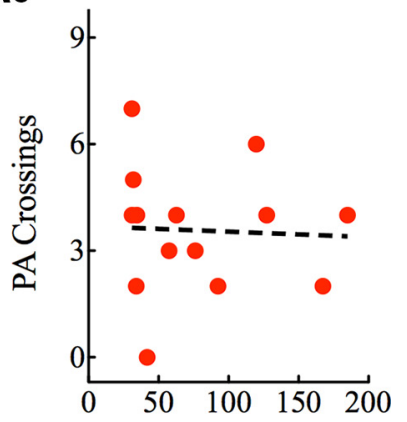

Distance in Kilometers
B1

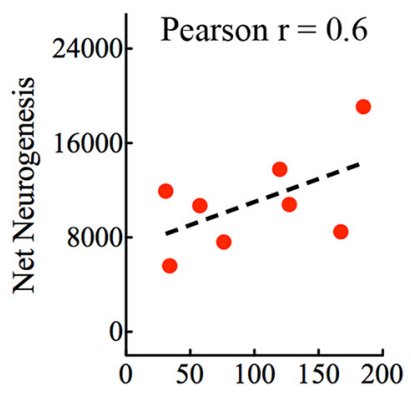

Distance in Kilometers

(4 Weeks of RE)

B2

Figure 4. Increasing running distance had no adverse effect on memory recall but proportionately enhanced hippocampal neurogenesis. $A_{1}-A_{6}$, Correlation curves between the extent of running and distinct measures of memory recall, such as latencies to the platform quadrant $\left(\mathrm{PQ} ; \boldsymbol{A}_{1}\right)$, platform area $\left(\mathrm{PA} ; A_{2}\right)$, and target area $\left(\mathrm{TA} ; \boldsymbol{A}_{3}\right)$, swim path lengths $\left(\mathrm{SPLs} ; \boldsymbol{A}_{4}\right)$ and dwell times $\left(\boldsymbol{A}_{5}\right)$ in the $\mathrm{PQ}$, and platform area crossings $\left(\boldsymbol{A}_{\boldsymbol{6}}\right)$. Longer running distance did not affect memory recall ability $\left(r^{2}=0.001-0.1\right) \cdot \boldsymbol{B}_{1}, \boldsymbol{B}_{2}$, Relationship between running distance over $4\left(\boldsymbol{B}_{1}\right)$ or 8 weeks $\left(\boldsymbol{B}_{2}\right)$ and the amount of neurogenesis using Pearson's correlation. Increasing numbers of newly born neurons emerge with greater running distance ( $\boldsymbol{B}_{1}$, Pearson's correlation coefficient $\left.r=0.6 ; \boldsymbol{B}_{2}, r=0.7\right)$.

Increasing amounts of running neither worsened nor improved memory recall

Regression curves were analyzed between the extent of running and various parameters of memory recall, such as latencies to the platform quadrant, and platform and target areas, SPLs and dwell times in the platform quadrant, and crossings of the platform area. These analyses revealed that increased levels of running neither worsened nor improved memory recall $(p>0.05$; Fig. 4 $\left.A_{1}-A_{6} ; n=14\right)$. Thus, the extent of voluntary RE performed by rats in this study did not affect their ability to recall memory.

Increasing amounts of running proportionately enhanced neurogenesis

The relationship between the extent of running accomplished in 4 or 8 weeks and the amount of neurogenesis was analyzed using
Pearson's correlation. Proportionally rising numbers of newly added neurons (net neurogenesis) was observed with longer running distances after 4 weeks of RE (Pearson's correlation coefficient, $r=0.6$; Fig. $4 B_{1} ; n=8$ ). A similar positive correlation was observed with 8 weeks of RE. Here, a correspondingly larger number of newly born $\mathrm{DCX}^{+}$neurons were noticed with longer running distances in the 8 week period ( $r=0.7$; Fig. $\left.4 B_{2} ; n=8\right)$. Thus, increased levels of running proportionately enhanced neurogenesis.

\section{Moderate and brisk runners displayed similar memory retrieval ability}

Because animals in the RE group displayed variable amounts of running over the first 4 weeks, we classified them into two subgroups, namely, moderate runners $(n=9)$ accomplishing an 


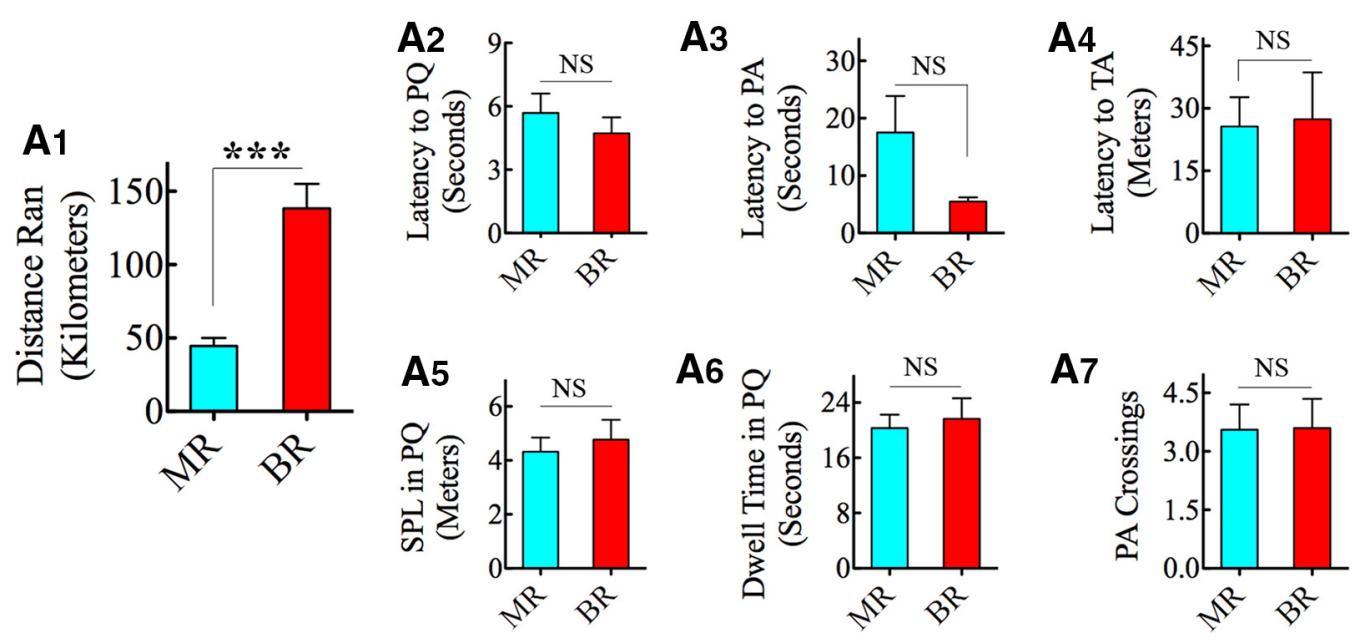

Figure 5. Memory retrieval ability remained similar between moderate runners (MR) and brisk runners (BR). $A_{1}$, Comparison of kilometers run by MR and BR, which differed significantly between the two groups $(p<0.001) \cdot A_{1}-A_{7}$, Comparison of the various parameters of memory recall, such as latencies to the platform quadrant $\left(P Q ; A_{2}\right)$, platform area $\left(P A ; A_{3}\right)$, target area $\left(T A ; A_{4}\right)$, swim path lengths $\left(S P L ; A_{5}\right)$ and dwell times $\left(A_{6}\right)$ in the $\mathrm{PQ}$, and platform area crossings $\left(A_{7}\right)$. Both moderate and brisk RE did not interfere with the recall of memory that was formed 4 weeks earlier. ${ }^{* * *} p<0.001$. NS, Not significant.

average of $44 \mathrm{~km}$ of running, and brisk runners $(n=5)$, achieving an average of $138 \mathrm{~km}$ of running (Fig. $5 A_{1}$ ). We next examined differences in their memory retrieval ability. Comparison of various parameters of memory recall, such as latencies to the platform quadrant, platform, and target areas; SPLs and dwell times in platform quadrants; and platform area crossings, revealed no differences between moderate runners and brisk runners $(p>$ 0.05; Fig. $5 A_{2}-A_{7}$ ). Thus, both moderate and brisk RE does not interfere with the recall of memory that was formed 4 weeks earlier.

\section{Discussion}

The results of this study emphasize that RE does not expunge hippocampus-dependent retrograde spatial memory in a rat model. This was revealed through analogous spatial memory recall capability 4 weeks after water maze learning between animals that performed RE and animals that stayed sedentary after learning. Notably, memory recall was preserved in RE animals despite 1.5- to 2.1-fold augmentation of hippocampal neurogenesis.

These results are in sharp contrast to an earlier elegant study in a mouse model, which suggested that an increased hippocampal neurogenesis mediated by RE leads to competitive circuit modification and results in forgetting (Akers et al., 2014). This study showed that: (1) very young (17 days old) mice demonstrating robust hippocampal neurogenesis exhibited deficient memory recall compared with adult mice displaying relatively decreased levels of neurogenesis; (2) manipulations that enhanced neurogenesis in adult mice (such as $\mathrm{RE}$ or administration of the drugs memantine or fluoxetine) caused a loss of retrograde memory; and (3) inhibition of RE-induced increased neurogenesis sustained normal memory retrieval function in adult mice. These results were demonstrated with both contextual fear conditioning and water maze paradigms, implying that an increased neurogenesis can erase both fear related memory as well as spatial reference memory. Although fear memory is initially hippocampusdependent, it can also be supported by extrahippocampal structures (Déry et al., 2015). Spatial reference memory, on the other hand, is permanently hippocampus-dependent (Snyder et al., 2005; Jessberger et al., 2009). Additional experiments showed that postnatal guinea pigs and degus (a rat-like rodent with a long silky coat) exhibited superior ability for memory recall than postnatal mice, seemingly due to somewhat lower levels of hippocampal neurogenesis in the postnatal period as a consequence of a longer gestation period in these animals. Furthermore, it was uncovered that manipulations that increased neurogenesis in guinea pigs and degus interfered with their memory recall ability (Akers et al., 2014). A follow-up study suggested that the weakening of existing memories by an increased hippocampal neurogenesis facilitates the encoding of new, conflicting information in mice (Epp et al., 2016).

The data presented by Akers et al. (2014) suggested a new concept that enhanced neurogenesis (resulting from lifestyle changes such as daily RE) is disadvantageous for memory recall. This suggestion is consistent with the memory clearance hypothesis that states increased synaptic incorporation of newly born neurons destabilizes preexisting synaptic connections storing encoded memories (Weisz and Argibay, 2012; Frankland et al., 2013; Mongiat and Schinder, 2014). As per this hypothesis, if a particular lifestyle (e.g., daily exercise) or intake of compounds or drugs that increase neurogenesis would result in the erasing of previously encoded memories, even though increased neurogenesis improves learning, cognitive flexibility, the ability for forming new memories, pattern separation and contextualization of information, and mood (Jacobs et al., 2000; Parihar et al., 2011; Kempermann, 2012a,b; Abrous and Wojtowicz, 2015; Kodali et al., 2015; Johnston et al., 2016). The above concept implies that the encoding of new memories without significantly erasing previously formed memories would require the right amount of hippocampal neurogenesis. However, the threshold at which augmented neurogenesis starts to obliterate previously formed memories is unclear. Furthermore, it is unknown whether increased neurogenesis-induced forgetting is common to all mammalian species.

We focused on a rat model because an increased neurogenesis-mediated forgetting of retrograde memories had not previously been examined in this species. Rats are also among the most favored species for assessing changes in cognition and memory in aging and neurological disorders because of the similarities in their physiology to humans and the perception that 
rats are more intelligent than mice (Iannaccone and Jacob, 2009). We examined whether voluntary RE-induced increased neurogenesis inhibits the recall of spatial reference memory in rats using a WMT. Animals that ran an average of $78 \mathrm{~km}$ during a 4 week period after water maze learning (RE animals) displayed comparable memory recall to animals that did not have access to running wheels (SED animals). Excellent memory recall in both groups was evinced through increased SPLs in the platform quadrant compared with the other three quadrants. Comparisons of multiple other parameters of memory recall also revealed no differences between the two groups. Indeed, comparison of platform area crossings showed better memory recall in animals belonging to the RE group than the SED group. Moreover, in comparison with SED animals, RE animals showed a 1.5- to 2.1fold increase in neurogenesis. Additionally, the production of newly born neurons increased proportionately with longer running distances, but memory recall ability remained similar between moderate runners (accomplishing $\sim 44 \mathrm{~km}$ of running) and brisk runners (achieving $\sim 138 \mathrm{~km}$ ). Thus, our results underscore that RE-induced increased neurogenesis does not impair the ability for recalling the previously formed spatial reference memory in a rat model.

What are the potential reasons for discrepancy in results between our study and the previous study by Akers et al. (2014)? It does not seem that there were major differences in the extent of neurogenesis after RE to differentially influence memory recall function between the two studies. In our study, animals in the RE group showed a 1.5- to 2.1-fold increase in neurogenesis, whereas in the study of Akers et al. (2014) the overall increase in neurogenesis after RE appeared to be $\sim 1.4$ fold. However, the running distance achieved in the 4 week running period differed greatly between the studies. Rats in our study ran an average of $2.8 \mathrm{~km} / \mathrm{d}$, whereas mice in the previous study ran an average of $4.7 \mathrm{~km} / \mathrm{d}$. This implies that rats can accomplish greater levels of neurogenesis through relatively modest $\mathrm{RE}$, whereas mice need extensive $\mathrm{RE}$ to boost neurogenesis. Is this difference in the amount of running the cause of the differential memory recall between the two species rather than increased neurogenesis alone influencing this function? This possibility is unlikely because Akers et al. (2014) demonstrated that the blunting of RE-induced increased neurogenesis in thymidine kinase mice through administration of ganciclovir diminished RE-induced forgetting.

Considering the above, it is likely that how increased neurogenesis affects memory recall varies in different species. Our study used a rat model, whereas the previous study used mouse, guinea pig, and degu prototypes. Although the degu is a rat-like rodent displaying more complex social behaviors, vocal communications, and manual dexterity than rats (Kumazawa-Manita et al., 2013), it is unknown whether the extent of changes in hippocampal neurogenesis over the lifespan after birth, memory encoding, and storage and retrieval patterns are comparable between degus and laboratory rats. Indeed, studies have shown that a number of fundamental features of circadian function differ considerably between degus and nocturnal laboratory rats (Lee, 2004) and the spontaneous development of signs of Alzheimer's disease is observed in degus between 12 and 36 months of age but not in rats (Ardiles et al., 2012; Deacon et al., 2015). Furthermore, there are substantial differences in the attributes of newly born neurons between rats and mice (Snyder et al., 2009). Newly born neurons in rats rapidly acquire mature neuronal markers, ex- press activity-induced immediate early genes, and display a reduced tendency to undergo death and an increased propensity for incorporation into learning and memory circuits, in comparison with their counterparts in mice (Snyder et al., 2009). Thus, it is plausible that newly born neurons in rats can encode new memories via the establishment of new synaptic connections without involving significant destabilization of the existing synapses. This phenomenon likely preserves previous memories that were strongly encoded, such as the spatial reference memory that is encoded and consolidated through multiple trials over many days.

The concept of forgetting due to RE-mediated increased neurogenesis needs to be examined thoroughly in multiple species for different types of memories, to fully understand the impact of such a phenomenon in people who perform rigorous exercise on a daily basis. In humans, multiple studies have shown that physical exercise induces transient and permanent brain changes at the structural and functional levels (Kramer et al., 2006; Hillman et al., 2008; Erickson and Kramer, 2009; Liu-Ambrose et al., 2012; Bherer et al., 2013), and that higher fitness levels are associated with a larger hippocampus and better spatial memory performance (Erickson et al., 2009; Kleemeyer et al., 2016). However, the direct effects of exercise or consequently increased neurogenesis on the recall of previously formed memories are unknown in humans. A recent study, however, found that people with lower stress and depression (presumably also exhibiting higher levels of neurogenesis) displayed better long-term retention of pattern separation memory than those with higher stress and depression scores (likely displaying lower levels of neurogenesis) (Déry et al., 2015), which indirectly suggested that higher levels of neurogenesis are associated with the stabilization of remote memories rather than enhanced forgetting.

In conclusion, our study using a rat model provides three novel findings. First, moderate exercise $(2.8 \mathrm{~km}$ of running per day) does not impair the recall of spatial reference memory formed earlier. Second, a 50\%-110\% increase in hippocampal neurogenesis (mediated by RE) does not weaken the ability to recall the spatial memory that was encoded before the commencement of exercise. Third, both moderate and brisk RE does not interfere with the recall of memory, even though brisk RE greatly enhances neurogenesis.

\section{References}

Abrous DN, Wojtowicz JM (2015) Interaction between neurogenesis and hippocampal memory system: new vistas. Cold Spring Harb Perspect Biol 7:10.1101/cshperspect.a018952. CrossRef Medline

Adlard PA, Perreau VM, Pop V, Cotman CW (2005) Voluntary exercise decreases amyloid load in a transgenic model of Alzheimer's disease. J Neurosci 25:4217-4221. CrossRef Medline

Ahn JH, Choi JH, Park JH, Kim IH, Cho JH, Lee JC, Koo HM, Hwangbo G, Yoo KY, Lee CH, Hwang IK, Cho JH, Choi SY, Kwon YG, Kim YM, Kang IJ, Won MH (2016) Long-term exercise improves memory deficits via restoration of myelin and microvessel damage, and enhancement of neurogenesis in the aged gerbil hippocampus after ischemic stroke. Neurorehabil Neural Repair. Advance online publication. Retrieved Mar 29, 2016. doi: 10.1177/1545968316638444. CrossRef Medline

Akers KG, Martinez-Canabal A, Restivo L, Yiu AP, De Cristofaro A, Hsiang HL, Wheeler AL, Guskjolen A, Niibori Y, Shoji H, Ohira K, Richards BA, Miyakawa T, Josselyn SA, Frankland PW (2014) Hippocampal neurogenesis regulates forgetting during adulthood and infancy. Science 344 : 598-602. CrossRef Medline

Ardiles AO, Tapia-Rojas CC, Mandal M, Alexandre F, Kirkwood A, Inestrosa NC, Palacios AG (2012) Postsynaptic dysfunction is associated with spatial and object recognition memory loss in a natural model of Alzheimer's disease. Proc Natl Acad Sci U S A 109:13835-13840. CrossRef Medline 
Bherer L, Erickson KI, Liu-Ambrose T (2013) A review of the effects of physical activity and exercise on cognitive and brain functions in older adults. J Aging Res 2013:657508. CrossRef Medline

Clark RE, Broadbent NJ, Squire LR (2007) The hippocampus and spatial memory: findings with a novel modification of the water maze. J Neurosci 27:6647-6654. CrossRef Medline

Costa V, Lugert S, Jagasia R (2015) Role of adult hippocampal neurogenesis in cognition in physiology and disease: pharmacological targets and biomarkers. Handb Exp Pharmacol 228:99-155. CrossRef Medline

Danker JF, Anderson JR (2010) The ghosts of brain states past: remembering reactivates the brain regions engaged during encoding. Psychol Bull 136:87-102. CrossRef Medline

Deacon RM, Altimiras FJ, Bazan-Leon EA, Pyarasani RD, Nachtigall FM, Santos LS, Tsolaki AG, Pednekar L, Kishore U, Biekofsky RR, Vasquez RA, Cogram P (2015) Natural AD-like neuropathology in octodon degus: impaired burrowing and neuroinflammation. Curr Alzheimer Res 12: 314-322. CrossRef Medline

Deng W, Aimone JB, Gage FH (2010) New neurons and new memories: how does adult hippocampal neurogenesis affect learning and memory? Nat Rev Neurosci 11:339-350. CrossRef Medline

Déry N, Goldstein A, Becker S (2015) A role for adult hippocampal neurogenesis at multiple time scales: a study of recent and remote memory in humans. Behav Neurosci 129:435-449. CrossRef Medline

Epp JR, Silva Mera R, Köhler S, Josselyn SA, Frankland PW (2016) Neurogenesis-mediated forgetting minimizes proactive interference. Nat Commun 7:10838. CrossRef Medline

Erickson KI, Kramer AF (2009) Aerobic exercise effects on cognitive and neural plasticity in older adults. Br J Sports Med 43:22-24. CrossRef Medline

Erickson KI, Prakash RS, Voss MW, Chaddock L, Hu L, Morris KS, White SM, Wójcicki TR, McAuley E, Kramer AF (2009) Aerobic fitness is associated with hippocampal volume in elderly humans. Hippocampus 19: 1030-1039. CrossRef Medline

Frankland PW, Köhler S, Josselyn SA (2013) Hippocampal neurogenesis and forgetting. Trends Neurosci 36:497-503. CrossRef Medline

Gomes FG, Gomes Da Silva S, Cavalheiro EA, Arida RM (2014) Beneficial influence of physical exercise following status epilepticus in the immature brain of rats. Neuroscience 274:69-81. CrossRef Medline

Hamilton GF, Rhodes JS (2015) Exercise regulation of cognitive function and neuroplasticity in the healthy and diseased brain. Prog Mol Biol Transl Sci 135:381-406. CrossRef Medline

Hattiangady B, Shetty AK (2008) Aging does not alter the number or phenotype of putative stem/progenitor cells in the neurogenic region of the hippocampus. Neurobiol Aging 29:129-147. CrossRef Medline

Hattiangady B, Shetty AK (2012) Neural stem cell grafting counteracts hippocampal injury-mediated impairments in mood, memory, and neurogenesis. Stem Cells Transl Med 1:696-708. CrossRef Medline

Hattiangady B, Kuruba R, Shetty AK (2011) Acute seizures in old age leads to a greater loss of CAl pyramidal neurons, an increased propensity for developing chronic TLE and a severe cognitive dysfunction. Aging Dis 2:1-17. Medline

Hillman CH, Erickson KI, Kramer AF (2008) Be smart, exercise your heart: exercise effects on brain and cognition. Nat Rev Neurosci 9:58-65. CrossRef Medline

Hötting K, Röder B (2013) Beneficial effects of physical exercise on neuroplasticity and cognition. Neurosci Biobehav Rev 37:2243-2257. CrossRef Medline

Hoveida R, Alaei H, Oryan S, Parivar K, Reisi P (2011) Treadmill running improves spatial memory in an animal model of Alzheimer's disease. Behav Brain Res 216:270-274. CrossRef Medline

Iannaccone PM, Jacob HJ (2009) Rats! Dis Model Mech 2:206-210. CrossRef Medline

Jacobs BL, van Praag H, Gage FH (2000) Adult brain neurogenesis and psychiatry: a novel theory of depression. Mol Psychiatry 5:262-269. CrossRef Medline

Jacotte-Simancas A, Costa-Miserachs D, Coll-Andreu M, Torras-Garcia M, Borlongan CV, Portell-Cortés I (2015) Effects of voluntary physical exercise, citicoline, and combined treatment on object recognition memory, neurogenesis, and neuroprotection after traumatic brain injury in rats. J Neurotrauma 32:739-751. CrossRef Medline

Jessberger S, Clark RE, Broadbent NJ, Clemenson GD Jr, Consiglio A, Lie DC, Squire LR, Gage FH (2009) Dentate gyrus-specific knockdown of adult neurogenesis impairs spatial and object recognition memory in adult rats. Learn Mem 16:147-154. CrossRef Medline
Ji ES, Kim YM, Shin MS, Kim CJ, Lee KS, Kim K, Ha J, Chung YR (2015) Treadmill exercise enhances spatial learning ability through suppressing hippocampal apoptosis in Huntington's disease rats. J Exerc Rehabil 11: 133-139. CrossRef Medline

Johnston ST, Shtrahman M, Parylak S, Gonçalves JT, Gage FH (2015) Paradox of pattern separation and adult neurogenesis: a dual role for new neurons balancing memory resolution and robustness. Neurobiol Learn Mem 129:60-68. CrossRef Medline

Kannangara TS, Lucero MJ, Gil-Mohapel J, Drapala RJ, Simpson JM, Christie BR, van Praag H (2011) Running reduces stress and enhances cell genesis in aged mice. Neurobiol Aging 32:2279-2286. CrossRef Medline

Kempermann G (2012a) New neurons for 'survival of the fittest.' Nat Rev Neurosci 13:727-736. CrossRef Medline

Kempermann G (2012b) Neuroscience: youth culture in the adult brain. Science 335:1175-1176. CrossRef Medline

Kempermann G, Song H, Gage FH (2015) Neurogenesis in the adult hippocampus. Cold Spring Harb Perspect Biol 7:a018812. CrossRef Medline

Kim DM, Leem YH (2016) Chronic stress-induced memory deficits are reversed by regular exercise via AMPK-mediated BDNF induction. Neuroscience 324:271-285. CrossRef Medline

Kleemeyer MM, Kühn S, Prindle J, Bodammer NC, Brechtel L, Garthe A, Kempermann G, Schaefer S, Lindenberger U (2016) Changes in fitness are associated with changes in hippocampal microstructure and hippocampal volume among older adults. Neuroimage 131:155-161. CrossRef Medline

Kodali M, Parihar VK, Hattiangady B, Mishra V, Shuai B, Shetty AK (2015) Resveratrol prevents age-related memory and mood dysfunction with increased hippocampal neurogenesis and microvasculature, and reduced glial activation. Sci Rep 5:8075. CrossRef Medline

Kramer AF, Erickson KI, Colcombe SJ (2006) Exercise, cognition, and the aging brain. J Appl Physiol 101:1237-1242. CrossRef Medline

Kumazawa-Manita N, Hama H, Miyawaki A, Iriki A (2013) Tool use specific adult neurogenesis and synaptogenesis in rodent (octodon degus) hippocampus. PLoS One 8:e58649. CrossRef Medline

Lee TM (2004) Octodon degus: a diurnal, social, and long-lived rodent. ILAR J 45:14-24. CrossRef Medline

Liu-Ambrose T, Nagamatsu LS, Voss MW, Khan KM, Handy TC (2012) Resistance training and functional plasticity of the aging brain: a 12month randomized controlled trial. Neurobiol Aging 33:1690-1698. CrossRef Medline

Liu X, Ramirez S, Pang PT, Puryear CB, Govindarajan A, Deisseroth K, Tonegawa S (2012) Optogenetic stimulation of a hippocampal engram activates fear memory recall. Nature 484:381-385. CrossRef Medline

Miller BR, Hen R (2015) The current state of the neurogenic theory of depression and anxiety. Curr Opin Neurobiol 30:51-58. CrossRef Medline

Mongiat LA, Schinder AF (2014) Neuroscience: a price to pay for adult neurogenesis. Science 344:594-595. CrossRef Medline

Parihar VK, Hattiangady B, Kuruba R, Shuai B, Shetty AK (2011) Predictable chronic mild stress improves mood, hippocampal neurogenesis and memory. Mol Psychiatry 16:171-183. CrossRef Medline

Parihar VK, Hattiangady B, Shuai B, Shetty AK (2013) Mood and memory deficits in a model of gulf war illness are linked with reduced neurogenesis, partial neuron loss, and mild inflammation in the hippocampus. Neuropsychopharmacology 38:2348-2362. CrossRef Medline

Rao MS, Shetty AK (2004) Efficacy of doublecortin as a marker to analyze the absolute number and dendritic growth of newly generated neurons in the adult dentate gyrus. Eur J Neurosci 19:234-246. CrossRef Medline

Rao MS, Hattiangady B, Abdel-Rahman A, Stanley DP, Shetty AK (2005) Newly born cells in the ageing dentate gyrus display normal migration, survival and neuronal fate choice but endure retarded early maturation. Eur J Neurosci 21:464-476. CrossRef Medline

Rao MS, Hattiangady B, Shetty AK (2006) The window and mechanisms of major age-related decline in the production of new neurons within the dentate gyrus of the hippocampus. Aging Cell 5:545-558. CrossRef Medline

Rao MS, Hattiangady B, Rai KS, Shetty AK (2007) Strategies for promoting anti-seizure effects of hippocampal fetal cells grafted into the hippocampus of rats exhibiting chronic temporal lobe epilepsy. Neurobiol Dis 27: 117-132. CrossRef Medline 
Richards BA, Frankland PW (2013) The conjunctive trace. Hippocampus 23:207-212. CrossRef Medline

Ryan SM, Kelly ÁM (2016) Exercise as a pro-cognitive, pro-neurogenic and anti-inflammatory intervention in transgenic mouse models of Alzheimer's disease. Ageing Res Rev 27:77-92. CrossRef Medline

Shetty AK, Hattiangady B, Rao MS, Shuai B (2012) Neurogenesis response of middle-aged hippocampus to acute seizure activity. PLoS One 7:e43286. CrossRef Medline

Snyder JS, Hong NS, McDonald RJ, Wojtowicz JM (2005) A role for adult neurogenesis in spatial long-term memory. Neuroscience 130:843-852. CrossRef Medline

Snyder JS, Choe JS, Clifford MA, Jeurling SI, Hurley P, Brown A, Kamhi JF, Cameron HA (2009) Adult-born hippocampal neurons are more numerous, faster maturing, and more involved in behavior in rats than in mice. J Neurosci 29:14484-14495. CrossRef Medline

van Praag H, Christie BR, Sejnowski TJ, Gage FH (1999) Running enhances neurogenesis, learning, and long-term potentiation in mice. Proc Natl Acad Sci U S A 96:13427-13431. CrossRef Medline

van Praag H, Shubert T, Zhao C, Gage FH (2005) Exercise enhances learning and hippocampal neurogenesis in aged mice. J Neurosci 25:86808685. CrossRef Medline

Weisz VI, Argibay PF (2012) Neurogenesis interferes with the retrieval of remote memories: forgetting in neurocomputational terms. Cognition 125:13-25. CrossRef Medline

Winocur G, Wojtowicz JM, Huang J, Tannock IF (2014) Physical exercise prevents suppression of hippocampal neurogenesis and reduces cognitive impairment in chemotherapy-treated rats. Psychopharmacology 231: 2311-2320. CrossRef Medline

Wong-Goodrich SJ, Pfau ML, Flores CT, Fraser JA, Williams CL, Jones LW (2010) Voluntary running prevents progressive memory decline and increases adult hippocampal neurogenesis and growth factor expression after whole-brain irradiation. Cancer Res 70:9329-9338. CrossRef Medline 